\title{
AS COISAS ESCRITAS NÃO \\ VÃO SER MAIS IMPORTANTES \\ QUE AS COISAS DESENHADAS \\ NAS FIGURAS: DIREITOS DE APRENDIZAGEM EM ARTE
}

Olga Egas ${ }^{1}$

Resumo

O Arte, uma palavra carregada de significações, dentro e fora da escola. Este artigo tece considerações sobre os Direitos de Aprendizagem em Arte para o Ciclo de Alfabetização (1 ${ }^{\circ}$, $2^{\circ}$ e $3^{\circ}$ anos) do Ensino Fundamental. Trata-se de assumir outra forma de conceber a educação, a escola, o professor, a infância e a arte na escola, apontando o protagonismo das ações infantis e a perspectiva de atribuição de significados ao mundo das culturas e da expressividade artística.

Palavras-chave: Direitos de Aprendizagem em Arte. Linguagem Artística. Acesso Cultural.

Toda criança tem direito de ter livros com figuras. As coisas escritas não vão se $r$ mais importantes que as coisas desenhadas nas figuras, nem vice-versa ao contrário, entendeu?

A exigência acima está, entre outras, na Declaração universal do moleque invocado, escrita em 2001, por Fernando Bonassi. Sob a ótica de um 'moleque invocado',

Professora Assistente da Faculdade de Educação, da Universidade Federal de Juiz de Fora/UFJF. Mestre em Artes pela Universidade Estadual Paulista Júlio de Mesquita Filho. 
porém, com sensibilidade e bom humor, o autor nos convoca a compreender o espaço e o lugar da criança no início deste novo milênio.

Segundo o moleque invocado, gente grande é nervosa, preocupada, apressada, boba, bestona, pão-dura, mal educada, egoista, cheia de frescuras e fricotes, chulezenta, esquisita, sem imaginação, mandona. Para o moleque invocado gente grande prefere ficar olbando no espelho do que olhar pelas janelas pra ver o que acontece com os outros. O moleque invocado também diz que entre as gentes grandes há pais e professores que merecem o certificado $A B G$ - adulto boa gente! E que estes deveriam estar nas escolas!

O tal moleque, fruto da imaginação do escritor, reivindica para si a liberdade de imaginar, brincar, experimentar e ter uma surpresa por dia. Nas entrelinhas, há o desejo de uma infância plena em experiências e afetos. E claro, a indignação diante da constatação de que nem todos os meninos e meninas vivenciam assim a infância.

Voltaremos às exigências do moleque invocado ao longo deste texto. Neste momento, ressaltamos que ele e todas as crianças do país têm direito às aprendizagens básicas como protagonistas das proposições para o Ciclo de Alfabetização, como afirma o documento Elementos conceituais e metodológicos para definição dos direitos de aprendizagem, publicado pelo MEC:

(...) Isto pressupõe que o protagonismo das ações esteja centrado nas crianças - seus modos de ser, agir, pensar, expressar-se e aprender, o que exige, necessariamente, que haja a revisão dos espaços e tempos escolares, das propostas pedagógicas, do uso dos materiais, do sistema de avaliação, das ofertas de apoio às crianças com dificuldade, do investimento na formação inicial e continuada dos professores, e nos vários aspectos que direta ou indiretamente influenciam no direito de aprender das crianças. (MEC, 2012, p. 18).

Ao destacar a frase As coisas escritas não vão ser mais importantes que as coisas desenhadas nas figuras, nem vice-versa ao contrário, entendeu?, iniciamos uma conversação sobre os 
Direitos de Aprendizagem em Arte. Sabemos bem que as coisas desenhadas nas figuras dizem do mundo tanto quanto as coisas escritas. Desde os tempos das cavernas, quando o ser humano usou, intencionalmente, cores, formas, espaços, superfícies, gestos, sons e movimentos para se comunicar com o outro e dar sentido a algo, compreendemos que a leitura de mundo não acontece apenas através das palavras. A música, o teatro, a pintura, a dança, o cinema, a poesia, etc., produzidas por diferentes povos, países e épocas são fontes vivas de atribuição de significados ao mundo das culturas, da produção artística e ao nosso eu particular.

Entender a arte como linguagem expressiva das formas sensíveis e subjetivas que compõem a humanidade, dá à expressão as coisas desenhadas nas figuras um sentido poético e ampliado. Empresto as palavras da formadora de arte-educadores, prof ${ }^{a}$ Rosa Iavelberg: "A arte promove o desenvolvimento de competências, habilidades e conhecimentos necessários a diversas áreas de estudos; entretanto, não é isso que justifica sua inserção no currículo escolar, mas seu valor intrínseco como construção humana, como patrimônio comum a ser apropriado por todos." (Iavelberg, 2003, p. 9)

Arte é conhecimento. Portanto, a arte é importante na escola, justamente porque é importante fora dela! "Privar o aluno em formação desse conhecimento é negar-lhe o que lhe é direito", alerta Iavelberg (2003, p. 9). O documento Elementos conceituais e metodológicos para definição dos direitos de aprendizagem, publicado pelo MEC, aponta alguns encaminhamentos para assegurar o direito à aprendizagem, entre os quais, destacamos

E, por fim, mas não menos importante, um trabalho que olhe para as crianças em suas potencialidades, em seus diferentes modos de aprender, em seus diversos ritmos, como processos subjetivos e não mais em suas carências; crianças consumidoras e também produtoras críticas de cultura, sujeitos de direitos - neste caso, direito de serem falantes/ouvintes, leitoras/escritoras, autônomas e autorais. (BRASIL, 2012, p. 19).
As coisas escritas não vão ser mais importantes que as coisas desenhadas nas figuras: direitos de aprendizagem em arte 
Trata-se de assumir outra forma de conceber a educação, a escola, o professor, a infância e a arte na escola. Esses são os grandes desafios: pensar a sala de aula como uma construção coletiva e individual de saberes; cultivar o olhar respeitoso em relação às singularidades das crianças e proporcionar situações de aprendizagem que incentivem o interesse, a curiosidade e o desejo de se tornarem produtoras críticas de cultura.

As crianças naturalmente gostam de descobrir e aprender. $\mathrm{Na}$ escola, o interesse por arte deve ser desenvolvido nas aulas, através de proposições desafiadoras que estimulem a participação diferenciada, a ampliação de repertório, a valorização e o incentivo à cooperação. Nesse sentido, nas tendências atuais do ensino da arte não há espaço para eleger entre as produções artísticas infantis a "mais bonita", "a melhor" ou qualquer outro tipo de competição improdutiva. No livro Teoria e Prática do Ensino de Arte: A língua do mundo, a professora Mirian Celeste apresenta reflexões importantes sobre esse tema no texto que transcrevemos abaixo:

\section{Desenhos de crianças brasileiras recusados em Milão?}

1948. No mesmo ano em que a importante Escolinha de Arte do Brasil era criada no Rio de Janeiro pelo artista e educador Augusto Rodrigues, foi realizada a Exposição Internacional de Arte Infantil, em Milão. A Comissão de seleção recebeu trabalhos de crianças dos vários continentes e todos os desenhos das crianças brasileiras foram recusados.

Aos olhos da comissão julgadora teríamos um subdesenvolvimento cultural? Um olhar europeu teria expectativas diferentes? A multiculturalidade não seria valorizada? Nenhuma dessas perguntas direciona para a resposta correta.

O músico Koellreuter e Geni Marcondes, que na época estavam na Itália, entrevistaram a vice-presidente da instituição organizadora. Em artigo publicado pelo O Estado de Minas de 1949, afirmam:

Quisemos saber qual fora o critério adotado para a escolha dos desenhos expostos. A Dra. Paccagnella respondeu-nos: 
"os mais espontâneos, naturalmente, foram os preferidos. Fizemos uma seleção na remessa de cada país e tudo o que pareceu ajudado, ou mesmo sugerido por adultos foi deixado de lado. No entanto, esse trabalho seletivo não pôde ser feito em relação aos desenhos vindos do Brasil. Como vêem - e a pedagoga sorriu gentilmente do nosso embaraço -, não tivemos muito que escolher. Não recebemos nenhuma criação verdadeiramente livre, das crianças brasileiras. Isso não quer dizer, é claro, que a infância do Brasil não sinta necessidade de usar também a linguagem gráfica, como a infância de todos os países do mundo. Apenas, creio que fizeram lá uma seleção completamente inversa da qual fizemos aqui. Preteriram as criações espontâneas pelos desenhos assim chamados 'bem feitinhos' e carentes de originalidade. Acharam, por certo, que isto aqui (e apontou um desenho de palmeiras feito com régua e apresentando uma perspectiva perfeita) era mais interessante do que uma criação deste tipo" (mostrou um desenho de um pequeno argentino, encantador, de liberdade inventiva). A Dra. Paccagnella tinha razão. Nada menos representativo, menos vivo, que as produções brasileiras da exposição. Era como se as nossas crianças tivessem nascido mortas e aqueles bichos empalhados fossem a representação de sua falta de vitalidade. (Escolinha de Arte do Brasil. Brasília, INEP, 1980. pag. 32.).

Os recusados, na verdade, não foram os desenhos das crianças brasileiras, mas os responsáveis pela seleção feita no Brasil. Provavelmente pensaram: "Se é para ir a Europa, não podemos enviar qualquer coisa!” $\mathrm{E}$ pais e professores deram a sua "ajudinha", a famosa "mão de gato"... E será que ela não está presente até hoje?

Aqueles desenhos mimeografados para colorir, presentes como atividades planejadas, tanto para crianças como para alunos de outros cursos de magistério em suas pastas de arte (arte?), são atestados de que não seriam capazes de fazer nada melhor.

No círculo vicioso, repetem-se as "mãos de gato", repetem-se os desenhos copiados. E, provavelmente, hoje seriam recusados também as produções, com aspecto de releitura, que copiam - e não inventam - Picasso ou Miró, os preferidos... (MARTINS. 2010, p. 13-14).

Assim, ainda hoje os professores quando impõem sua “ajudinha”, a tal "mão de gato", mesmo bem intencionados, destituem das produções artísticas realizadas na escola - a

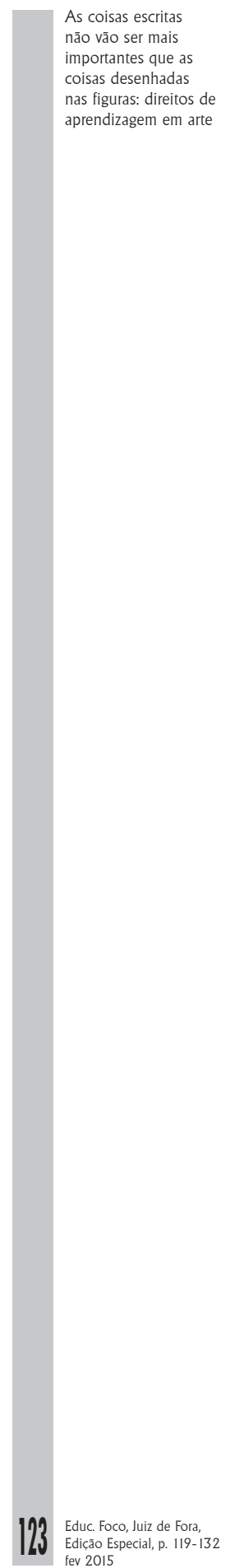


criação espontânea e livre das crianças, como aponta o texto acima. Ao interferirem na criação infantil com a racionalidade do olhar adulto, por vezes engessado nos clichês dos antigos álbuns de desenhos didáticos dos cursos de formação para o magistério, os professores estabelecem padrões estéticos estereotipados e sem significado para o universo das crianças. De certo modo, coincidindo com o Ciclo de Alfabetização, esses padrões inauguram um adestramento e a perda da criatividade, impedindo a mão e o olhar da criança de brincar e experimentar. Insatisfeita com sua própria produção as crianças, cerceadas pelo julgamento estético de certo/errado, bonito/feio do adulto professor, vão aos poucos, escondendo sua originalidade e singularidade.

Segundo Piaget, a criatividade é muito importante porque através dela compreendemos o mundo e o interpretamos à nossa maneira. Alunos e professores precisam de distintas oportunidades para descobrir e interpretar a realidade que conhecem ou possam vir a conhecer. Vale a pena refletir sobre a presença da "mão de gato" em sua sala de aula e o seu modo pessoal de lidar com as potencialidades/carências individuais dos seus alunos. Como professor, suas intervenções nos momentos de arte na escola, podem fazer aflorar a vitalidade, a espontaneidade e a liberdade inventiva de todas as crianças, não é mesmo?

Essa atitude pedagógica potencializa a ampliação e o enriquecimento da área de Linguagem. É exatamente isso que encontramos no documento Elementos conceituais $e$ metodológicos para definição dos direitos de aprendizagem:

O trabalho com a área de Linguagem (Língua Portuguesa, Arte e Educação Física) parte do princípio de que a criança, desde bem pequena, tem infinitas possibilidades para o desenvolvimento de sua sensibilidade e de sua expressão. Um dos grandes objetivos do currículo nessa área é a educação estética, isto é, sensibilizar a criança para apreciar uma pintura, uma escultura, assistir a um filme, ouvir uma música. (...) Ainda na área das Linguagens, é preciso assegurar um ensino pautado por uma prática pedagógica que 
permita a realização de atividades variadas, as quais, por sua vez, possibilitem práticas discursivas de diferentes gêneros textuais, orais e escritos, de usos, finalidades e intenções diversos. (BRASIL, 2012, p. 24)

Segundo o moleque invocado, toda criança tem o direito a aprender a lingua que quiser, mesmo que seja a lingua das borboletas, lobos, corujas, peixes, árvores, bolinhas de gude ou pedras. Atenção: língua de sogra também pode. E você, professor, gostaria de aprender a língua do vento, das marés, do sabiá, do tamanduá ou a língua dos sinais? Ah! Também tem a língua de trapo... O moleque invocado também disse que toda criança tem o direito de inventar três linguas secretas! Mas, a língua do mundo é a Arte, abarrotada de cores, formas, sons, ritmos e movimentos. Essa língua que desconhece fronteiras, etnias, credos, épocas - existe em todo o mundo e para todo mundo. Desde sempre, a arte nos acompanha e nos representa em nossa humanidade.

A verdade é que a arte não envelhece porque o ser humano que a contempla é sempre novo, ou terá um olhar outro e estará realizando uma infinidade de leituras porque infinita é a capacidade do homem de perceber, sentir, pensar, imaginar, emocionar-se e construir significações diante das formas artísticas e culturais. (MARTINS. 2010, p. 61).

Manter-se aberto ao novo, aprender, compreender e fazer uso da linguagem artística nos coloca diante de saberes e fazeres que possibilitam elaborar pensamentos sobre nós mesmos, em interação com o outro e nossas influências culturais. Um modo único de despertar a consciência e novos modos de sensibilidade.

Os Elementos conceituais e metodológicos para definição dos direitos de aprendizagem e desenvolvimento do ciclo de alfabetização apontam para a compreensão da linguagem e a construção dessa consciência e sensibilidade ao reiterar a importância de integrar ao contexto pedagógico a interdisciplinaridade, a ludicidade, a imaginação, como destacamos no trecho a seguir:
As coisas escritas não vão ser mais importantes que as coisas desenhadas nas figuras: direitos de aprendizagem em arte 


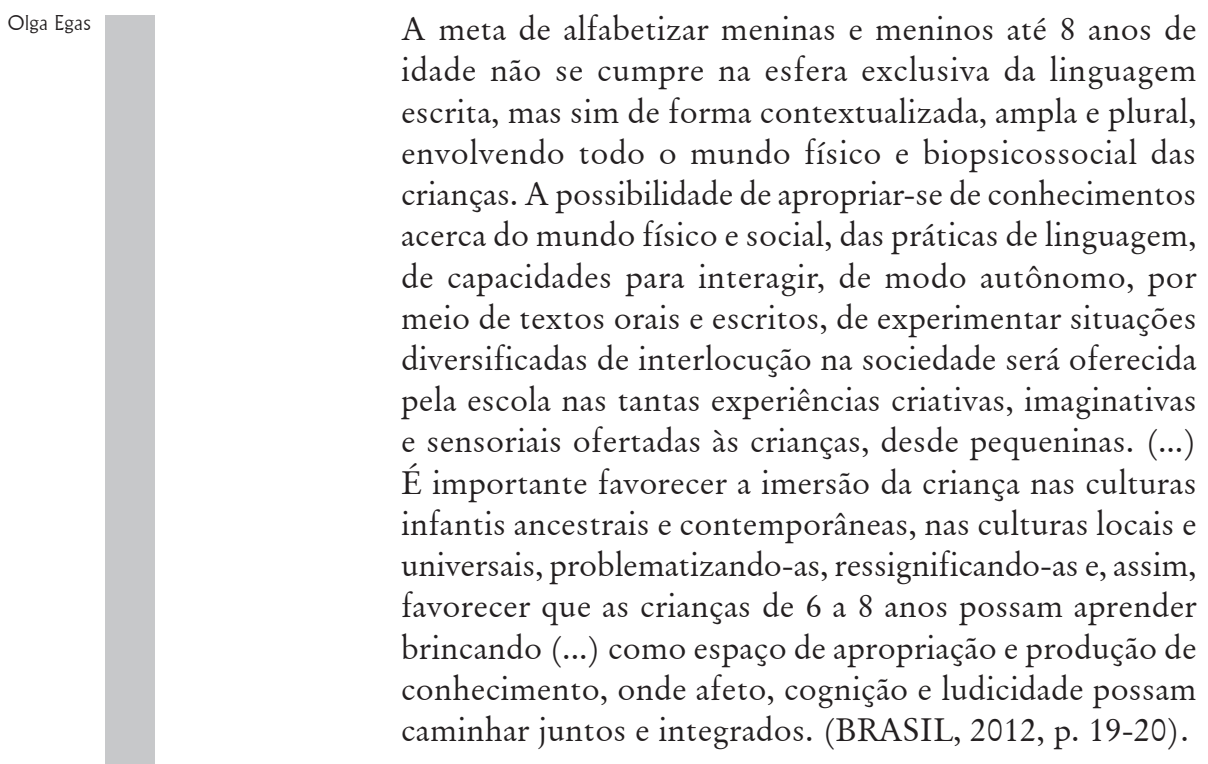

Trazemos mais uma reivindicação do moleque invocado: Toda criança tem direito a 8 horas de estudo, 8 horas de sono e 8 de brincadeira por dia, sendo que a escola tem de ser tão (ou até mais!) divertida quanto a brincadeira e tão (ou até mais) gostosinha que dormir uma soneca daquelas boas mesmo. Esse moleque invocado deseja uma escola alegre e acolhedora onde cada aula seja como um jogo de aprender e ensinar, entre o educador animado, crianças curiosas com olhos brilhantes e situações de aprendizagens significativas.

Quando se fala de crianças de 6 a 8 anos, do Ciclo da Alfabetização, não se pode então deixar de sublinhar a brincadeira como uma de suas formas expressivas - maneira singular de relação da criança com o mundo; uma das mais significativas expressões da cultura e da identidade infantil. Ainda nesta direção, pensar em um processo de alfabetização ampliado é considerar as diferentes linguagens da Arte e as possibilidades e expressões do corpo, o que requer refletir criticamente sobre a maneira como a criança vivencia seus cotidiano escolar e cotidiano: em casa, na comunidade, na sociedade. (BRASIL, 2012, p. 118).

Não é que o moleque invocado tem razão, entre as horas de sono, estudo, brincadeira: desvelar/ampliar e 
propor desafios estéticos são como poções mágicas, pó de pirlimpimpim...

O professor do Ciclo de Alfabetização precisa resgatar seu compromisso de saber ser educador, "guloso em seu desejo de ensinar, paciente na oferta e na espera de quem acredita e confia no outro e amoroso no compartilhar de saberes" (MARTINS, 2010, p. 129). Para garantir os Direitos de Aprendizagem e Desenvolvimento da Área de Linguagem - Arte e Educação Física, é preciso identificar e compreender os conhecimentos básicos, os eixos estruturantes e objetivos de aprendizagem. Sugerimos a leitura atenta do documento completo, que sintetizaremos a seguir.

Os saberes dos componentes Arte e Educação Física precisam:

proporcionar às crianças vivências e experiências com a arte e com a expressão corporal que envolvam seu mundo físico, social, cultural. As experiências devem contemplar apreciação, execução, criação e reflexão nas diferentes linguagens da Arte - cantando, tocando, pintando, desenhando, dançando, interpretando, encenando -, bem como em diferentes manifestações da cultura corporal jogando, brincando com os elementos da ginástica, criando - de maneira a também conhecer, (re)criar e ampliar suas possibilidades de expressão. Assim, tem-se em vista que a criança possa compreender e produzir ações com vistas à sua participação autônoma, em variadas esferas sociais de interação. (BRASIL, 2012, p. 115).

No documento, a área de Linguagem estabelece aproximações entre Arte e Educação Física, reconhecendo as especificidades dos diferentes componentes. Mas, considera a criança, sobretudo aquela do Ciclo da Alfabetização, como um ser que aprende em movimento. Sabemos disso quando constatamos que nossos alunos cantam e dançam o tempo todo, precisam andar pela sala de aula, nem que seja para jogar a pontinha do lápis grafite e adoram o recreio - quando enfim, são ou deveriam ser livres e donos de si. Nos espaços escolares, a Educação Física e a Arte, quando atendem os Direitos e Objetivos de Aprendizagem e Desenvolvimento,
As coisas escritas não vão ser mais importantes que as coisas desenhadas nas figuras: direitos de aprendizagem em arte 
exploram o dinamismo das crianças, provocam a experimentação cênica, visual, musical e corporal, com as obras literárias, teatrais, musicais, visuais e coreográficas, ou ainda os jogos e as brincadeiras que impulsionam a imaginação.

Tais experiências para crianças de 6 a 8 anos do Ciclo de Alfabetização, como dito anteriormente, ocorrem através da apreciação, execução, criação e reflexão, como recomenda o documento:

- Apreciação pressupõe relacionar-se, de forma lúdica e imaginativa ao que está sendo visto, ouvido, sentido e vivido nas diferentes produções e criações de outras pessoas ou grupos.

- As experiências de execução são inseparáveis das experiências de criação, de maneira a valorizar sua autoria e processo criador.

- A criação requer o diálogo da criança com seu repertório de experiências, saberes e fazeres, e sua imaginação, considerando seus processos de identidade e de alteridade, exigindo, assim, autonomia de pensamento e ação.

- Conhecer-se e se apropriar de algo é também pensar criticamente sobre ele, compará-lo, fazer associações de ideias. É o conhecimento de si e do outro. A busca de significação diante de expressões da cultura corporal e das linguagens da Arte mobiliza os conhecimentos que se tem sobre si mesmo - isto é, sua identidade. Da mesma forma, na alteridade, as linguagens da Arte e as manifestações da cultura corporal mobilizam o conhecimento e a reflexão em relação ao outro, num processo permanente de reconhecer-se, estranhar-se, diferenciar-se. (BRASIL, 2012, p. 116).

Quando o professor do Ciclo de Alfabetização acolhe genuinamente os processos de apropriação e reflexão das crianças, suas hipóteses, comentários, percepções e ideias sobre si e sobre o mundo, impulsiona o percurso pessoal e coletivo de produção de sentidos dos alunos. Imersos na parceria e no diálogo, professor e alunos vivenciam experiências de apreciação, produção e criação nas diferentes linguagens artísticas (teatro, música, dança e artes visuais). 
Diferentemente do que se faz na vida cotidiana, a experiência estética é aquela que faz entender que as crianças (e também os professores) não conhecem o mundo apenas pensando nele, pois tudo é percebido, valorado e pela experiência do mundo sensível. Ainda neste contexto, cabe sublinhar que a experiência estética, na escola, não visa estimular a formação de artistas - sejam eles músicos, artistas plásticos, atores ou dançarinos -, mas tornar os sujeitos mais sensíveis, apreciadores, conhecedores e criadores nas/ das diferentes linguagens e expressões humanas. (BRASIL, 2012, p. 119).

A experiência estética no campo da Arte tem algo de essencial, sensível e potente. Não é apenas o encontro com o Belo, mas também com o estranhamento, a problematização, o contato e a descoberta... "A experiência é o que nos passa, o que nos acontece, o que nos toca. Não o que se passa, não o que acontece, ou o que toca" (LARROSA, 2004, p. 154). Às vezes a experiência estética pode ser uma explosão visceral ou chegar sem pressa, invadindo nossos sentidos e se revelando aos poucos. Acometida pela descoberta da experiência estética, as crianças sorriem, abraçam umas às outras, gritam euforicamente ou ainda se isolam em algum canto. Fundamental na experiência é a disponibilidade, a percepção aguçada e o envolvimento pessoal. $\mathrm{Na}$ sala de aula, o professor que compreende essa atitude pedagógica possibilita diálogos internos, enriquecidos pela socialização dos saberes e das perspectivas pessoais e culturais de cada produtor/fruidor/aprendiz.

O moleque invocado esperneia mais uma vez, gritando para quem quiser ouvir: É proibido que alguém tenha falta de alguma coisa. Se uma criança tiver falta de alguma coisa que ainda não saiba o que é tem o direito de ligar as luzes de toda a casa e acordar todo mundo pra perguntar e tentar saber o que ela está querendo mas ainda não sabe. Assim, do moleque invocado às crianças do Ciclo de Alfabetização deste país, todas sem distinção, têm Direitos e Objetivos de Aprendizagem e Desenvolvimento, como
As coisas escritas não vão ser mais importantes que as coisas desenhadas nas figuras: direitos de aprendizagem em arte 
I. Ter acolhidas suas experiências, saberes e fazeres corporais, sensíveis e reflexivos.

II. Ser incluídas e valorizadas nas práticas educativas de Educação Física e Arte, independente de suas características corporais, expressivas e étnico-culturais.

III. Ter ampliadas suas experiências, saberes e fazeres por meio do acesso aos diferentes modos como a Arte e Educação Física vêm sendo produzidas ao longo do tempo no seu entorno, no Brasil e no mundo.

IV. Ter ampliadas suas experiências, saberes e fazeres por meio de suas possibilidades expressivas na Arte e na Educação Física.

V. Ter asseguradas práticas educativas lúdicas - que incluam brincadeiras e jogos - na realização de propostas visuais, sonoras, dramáticas e corporais.

VI. Ter impulsionada sua imaginação e seus processos criadores nas propostas educativas de Educação Física e das diferentes linguagens da Arte: música, teatro, dança e artes visuais.

Pensar o ensino de arte é também pensar o processo de poetizar, fruir e conhecer arte. Trata-se de valorizar a herança cultural, artística e estética das crianças, ampliar olhares, possibilitar diferentes conexões entre arte e cultura. Como prevê o documento, as aprendizagens gerais da arte, elencadas no quadro abaixo, contemplam as especificidades das linguagens artísticas ao mesmo tempo em que apontam ao professor caminhos possíveis para currículos contemporâneos para a arte no Ciclo de Alfabetização do Ensino Fundamental. (Figura 1).

Voltando ao nosso moleque, ele afirma em verdade verdadeira que: Toda criança tem o dever de continuar criança, mesmo depois de grande! Uhuuuu!! 


\begin{tabular}{|c|c|c|c|}
\hline Direitos gerais de aprendizagem: Arte & Ano 1 & Ano 2 & Ano 3 \\
\hline $\begin{array}{l}\text { Comprender a arte cama um canhecimenta produzida sacialmen- } \\
\text { te, em diferentes conteutas historicas e culturais } \mathrm{d} \text { a humanidade. }\end{array}$ & I/A & A & $c$ \\
\hline $\begin{array}{l}\text { Reconhecera importë ncie sacial de erte ne saciedade e ne vida } \\
\text { dos individuas. }\end{array}$ & I/A & A & $c$ \\
\hline 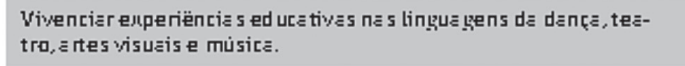 & $\mid / A / C$ & $A / C$ & $C$ \\
\hline 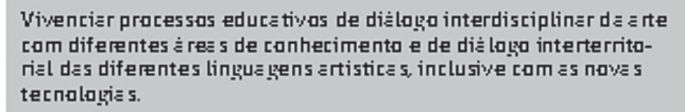 & $\mathrm{I} / \mathrm{A} / \mathrm{C}$ & $A / C$ & C \\
\hline 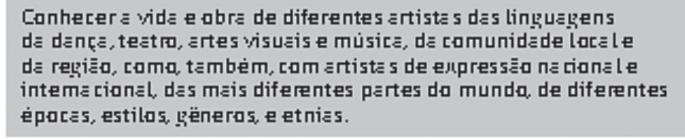 & I/A & $A / C$ & $c$ \\
\hline Convivere e cesser fantes vives de praduçä̀ de erte. & I/A/C & AIC & $c$ \\
\hline 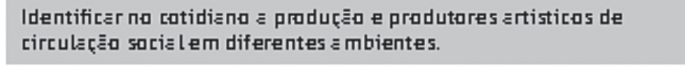 & I/A/C & $A / C$ & $c$ \\
\hline $\begin{array}{l}\text { Ler, apreciare a nalisar criticamente diferentes objetos artisticose } \\
\text { manifesteçâes da arte na sociedade. }\end{array}$ & $\mathrm{I} / \mathrm{A} / \mathrm{C}$ & $A / C$ & C \\
\hline $\begin{array}{l}\text { Conhecere recanhecer as elementas que constituem as lingue- } \\
\text { gens artistices a partir da leiture e enélise de abjetas artistikos. }\end{array}$ & I/AIC & $A / C$ & $c$ \\
\hline 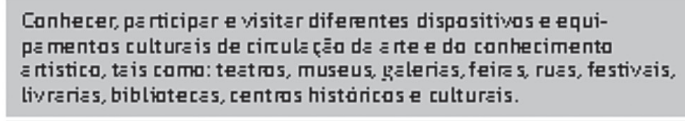 & I/A/C & $A / C$ & C \\
\hline $\begin{array}{l}\text { Fezer a rte ne perspective de crie çäo artistice coma pesquise e } \\
\text { inyestigeça. }\end{array}$ & I/A/C & $A / C$ & $c$ \\
\hline 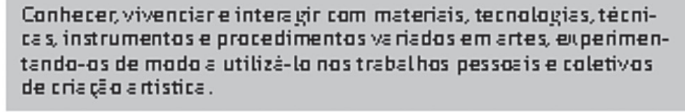 & I/A/C & $A / C$ & $c$ \\
\hline $\begin{array}{l}\text { Pesquisar e angenizar as diferentes canhecimentos artisticos, a } \\
\text { partir de fontes } y=\text { riadas de informe çäes. }\end{array}$ & I/A/C & $A / C$ & c \\
\hline 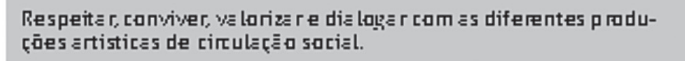 & $\mid / A / C$ & $A / C$ & $C$ \\
\hline
\end{tabular}

I-Introduzir; A- Aprofundar; C - Consalidar.

Figura 1 - PNAIC - Alfabetização para todos: diferentes percursos, direitos iguais. Vol. 1 Unidade 07, pág. 23.

\section{REFERÊNCIAS}

BONASSI, Fernando. Declaração Universal do moleque invocado. São Paulo: Cosac \& Naify. 2003.

BRASIL. Ministério da Educação. Secretaria de Educação Básica. Diretoria de Currículos e Educação Integral DICEI. Coordenação Geral do Ensino Fundamental - 
COEF. Elementos conceituais e metodológicos para definição dos direitos de aprendizagem e desenvolvimento do ciclo básico de alfabetização $\left(1^{\circ}, 2^{\circ}\right.$ e $3^{\circ}$ anos) do ensino fundamental. Brasília, DF: MEC, 2012.

- Ministério da Educação. Secretaria de Educação Básica. Diretoria de Apoio à Gestão Educacional. Pacto nacional pela alfabetização na idade certa: alfabetização para todos: diferentes percursos, direitos iguais: ano 01, unidade 07. Brasília, DF: MEC, SEB, 2012.

IAVELBERG, Rosa. Para gostar de aprender arte: sala de aula e formação de professores. Porto Alegre: Artmed, 2003. LARROSA, Jorge. Linguagem e educação depois de Babel. Belo Horizonte, MG: Autêntica, 2004.

MARTINS, Mirian Celeste. PICOSQUE, Gisa. GUERRA, M Terezinha. Teoria e Prática do Ensino de Arte. A língua do mundo. São Paulo: FTD, 2010.

WRITTEN THINGS WILL NOT BE MORE IMPORTANT THAN THINGS DRAWN IN FIGURES: LEARNING RIGHTS IN ART 